\title{
THE INFLUENCE OF COSTAL AND ABDOMINAL PRESSURE ON THE ACTION OF THE DIAPHRAGM IN NORMAL AND EMPHYSEMATOUS SUBJECTS*
}

\author{
BY \\ H. HERXHEIMER \\ From the Surgical Unit, University College Hospital, London
}

The use of pressure on the abdomen by an abdominal belt has been advocated by Christie (1933) and by Alexander and Kountz (1934) for the treatment of emphysema. Warner and Doidge (1939) have employed a costal belt for the same purpose. Both kinds of treatment were successfully used in some patients only, and as it is the aim of the treatment to influence the range of the diaphragm it seemed useful to examine this influence in a number of normal and emphysematous subjects.

\section{METHOD}

The level of the diaphragm was determined by its distance from the iliac crests (Warner and Doidge, 1939). The details of this method, which we have used previously for the measurement of the diaphragmatic level in emphysema, are described elsewhere (Grossmann and Herxheimer, 1948). In the present experiments the highest and the lowest level that could be reached by the diaphragm in maximum expiration and inspiration, and also the range of movement during quiet breathing, were measured in the sitting and in the supine positions. The same measurements were taken during costal and abdominal pressure. The pressure was applied by a canvas belt $12 \mathrm{~cm}$. in width, which was fastened round the chest with its upper margin in the axillae or round the abdomen. In order to produce sufficient compression a pad was placed underneath the abdominal belt. The degree of pressure could not be standardized; the belt was put on firmly enough to cause such a degree of discomfort in breathing as the subject believed he could not tolerate easily for longer than from thirty to sixty minutes. In other experiments very moderate pressure was used, of a degree which the subject believed he could tolerate for an indefinite time. The emphysematous patients proved less tolerant to the pressure than normal subjects.

Respiratory tracings were taken with a recording spirometer of the Benedict-Roth type ; this was fitted with a flow-meter permitting a continuous replace-

*From the Surgical Unit, University College Hospital, London. ment of the oxygen used; a horizontal tracing was thus obtained. The vital capacity was recorded three times in each position and the mean of these three values was taken. The subjects had been trained previously to breathe through mouthpiece and valves; subjects - who could not reproduce consistently the same vital capacity (within an arbitrary range of $150 \mathrm{ml}$.) were excluded.

Eight medical students (six men and two women), who were in normal health, and thirty-four patients were investigated. Of the latter, sixteen suffered from severe and nine from moderate emphysema; nine others were obese asthmatics. The diagnosis "emphysema" was supported in all cases by a typical history of long-standing cough and increásing breathlessness on exercise: congestive failure, tuberculosis, and malignant disease of the chest were excluded. In many cases the typical clinical signs of emphysema were present. The differentiation between severe and moderate emphysema was made according to the disability of the patient. Those who showed breathlessness on moderate exertion-walking at normal speed on even ground-were regarded as severe; those who only showed breathlessness, at increased speed or on the up-grade were regarded as moderate. As a rule in the latter the vital capacity was normal or approximately normal, whilst in the former it was much reduced.

A further group includes nine obese asthmatic patients. They were in a subacute asthmatic state, but their history of asthma was comparatively short and did not exceed ten years. It was assumed that some degree of emphysema was present.

\section{RESULTS}

Maximum range of diaphragmatic movement.The average results for each group of patients are given in Fig.' 1 . In this figure the base line represents the level of the iliac crests, and the columns rising from the base line are divided into two parts. The lower part shows the distance from the iliac crests to the inspiratory (lowest) diaphragmatic level; the upper shows the maximum range of diaphragmatic movement from the lowest (inspiratory) to the highest (expiratory) limit. The first 


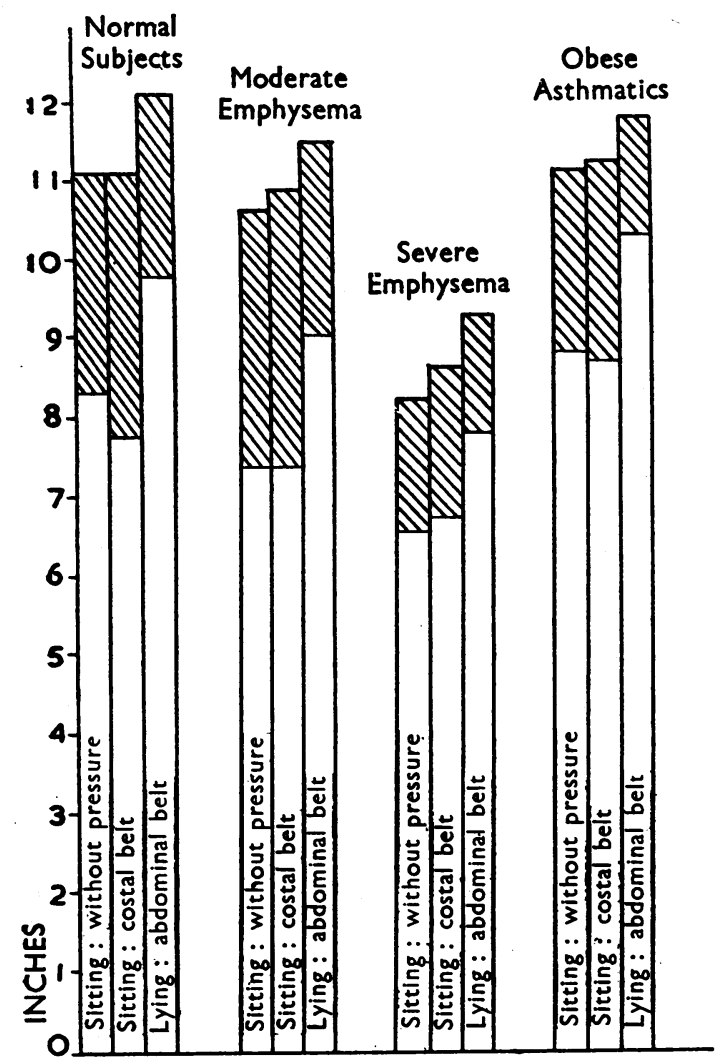

FIG. 1.-Maximum range of diaphragmatic movements in relation to iliac crest level (iliac crest level = 0 inches). The upper border line of the shaded area represents the expiratory, the lower border line the inspiratory limit.

column in each group gives these distances in the sitting position, the second in the position of sitting during costal-belt pressure, the third in the supine position during abdominal pressure. The results obtained sitting, during abdominal-belt pressure, supine, without pressure, and during costal pressure have been omitted as they do not show more than the results given.

The normal subjects show that the diaphragm can change its range under pressure. If the inspiratory movement of the ribs is restricted by the costal belt, the diaphragm can be lowered more than was possible before. The total range of movement thus increases and makes good some of the loss of breathing capacity incurred by the partial immobilization of the ribs. On the other hand, with the abdominal belt, the diaphragm cannot be lowered as much as before ; but in expiration it can be pushed up much higher into the thorax-one has the impression that the belt is used as a support against which the abdominal muscles can press to push the diaphragm more efficiently upwards.

If we compare the third group-severe emphysema - with the normal subjects, two differences are obvious: the inspiratory level of the diaphragm is much lower, and its range of movement is halved. But there are other differences; costal pressure does not enable the patient to move the diaphragm further down, as in normal subjects (it is so low already that no effort can get it lower). In some of the patients the level even rises a little. This is due to the fact that the dyspnoea caused by the belt leads to a further extreme inspiratory effort after the diaphragm has reached its lowest point. This results in the lifting of the whole of the thorax, including the low diaphragm. This phase can easily be followed on the screen.

When abdominal pressure is used, the highest expiratory level of the diaphragm in these patients lies three inches below that of the normal subjects. One might have expected that this sustained pressure would push the diaphragm, held down by the over-inflated lung tissue, high up into the chest; but this is not the case. There may be two different reasons for this behaviour. Either there is a continuous bronchial spasm which keeps the lungs rigidly inflated without interruption and prevents the diaphragm from being moved upwards. This is improbable, as bronchial spasm is never constant, and a continuous pressure would expel sufficient air to allow a greater range of diaphragmatic movement. If, however, the diaphragm had

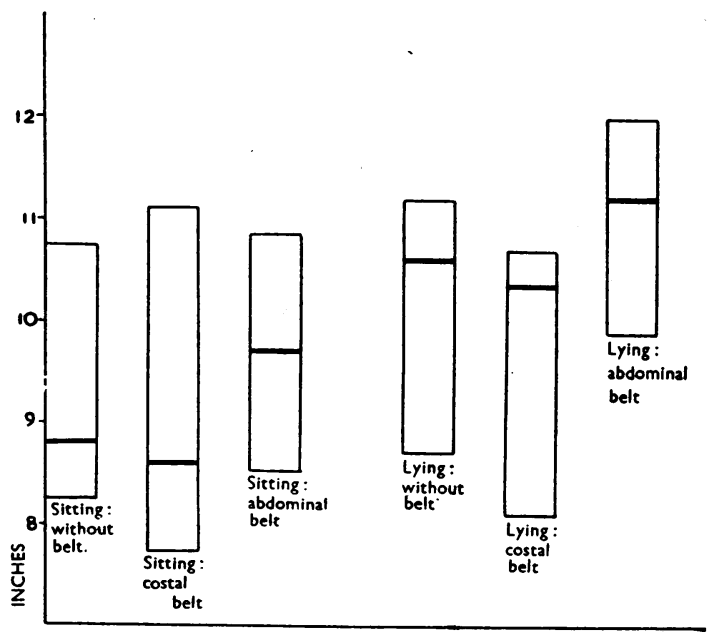

FIG. 2.-Subject A. The thick horizontal line indicates the mean diaphragmatic level during quiet breathing in relation to its extreme range. The scale on the left gives the distance from the iliac crests in inches. 
lost some of its muscular quality through atrophy or fibrosis, it would not be able to relax to a high level.

The patients suffering from moderate emphysema lie about midway between the normal subjects and the severe cases. The inspiratory level is already lower than normal, and physical effort cannot lower it further. But the range of the diaphragmatic movement is unimpaired (hence the normal vital capacity) and the abdominal pressure shows a fairly good mobility of the diaphragm.

The diaphragmatic level of the obese asthmatics is about the same as in normal subjects. The range is somewhat restricted, and the diaphragm cannot be lowered, this indicating that the lowest level has been reached. But under abdominal

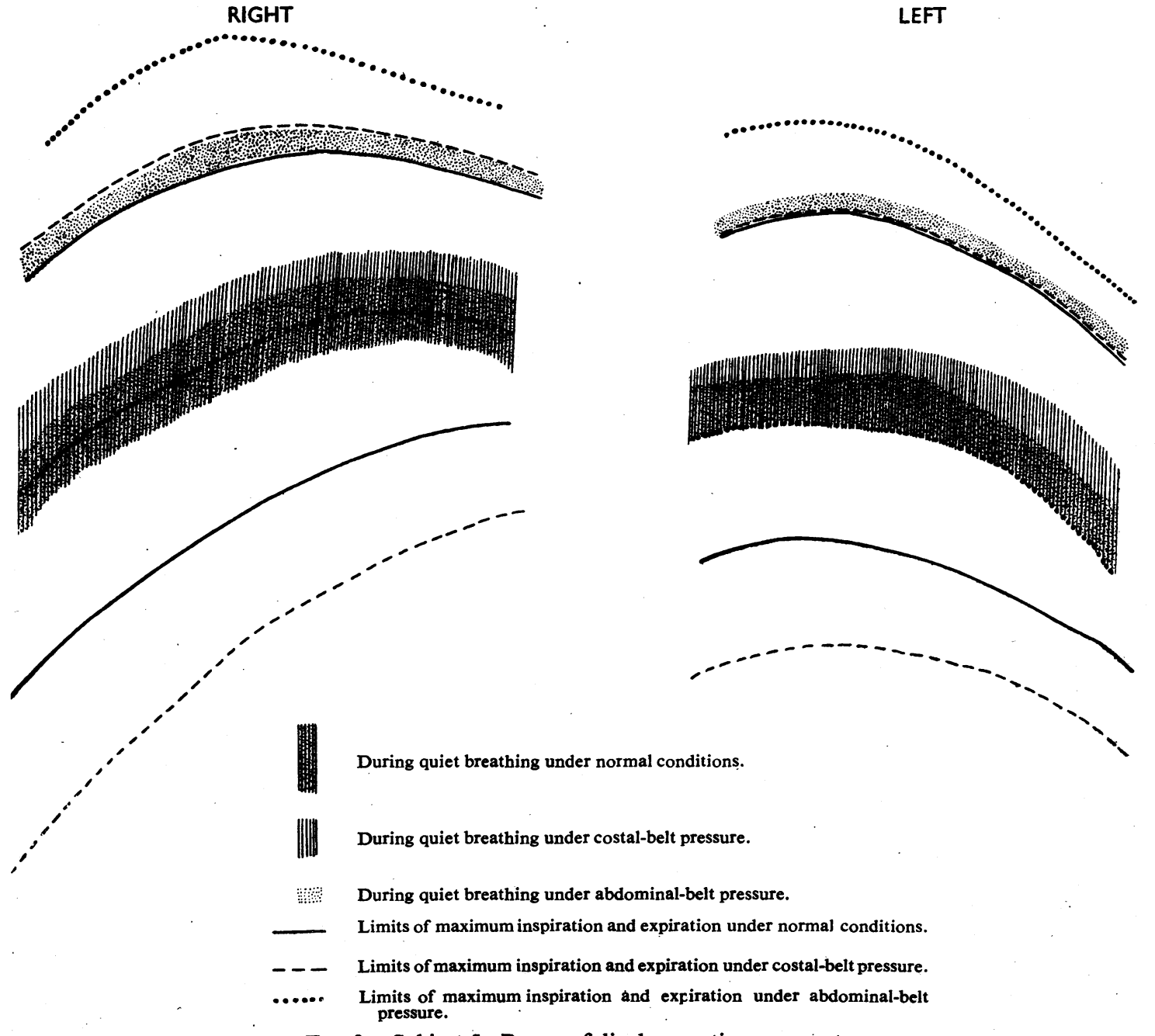

pressure the diaphragm can be lifted satisfactorily. The individual variations leading to the average values given in Fig. 1 were comparatively small. The total range was \pm 10 per cent in the normal subjects and \pm 16 per cent in the emphysematous patients. In the normal group there is only one subject in whom the diaphragm could not be lowered on costal pressure. In the group of the moderately emphysematous it could be lowered in some, and it rose in others. In the group of patients suffering from severe emphysema there were only two patients in whom the diaphragm did not rise or in whom it remained unchanged on costal pressure.

Position of the diaphragm during quiet breathing.-Under normal conditions the diaphragmatic

\section{LEFT}

Fig. 3.-Subject 5. Range of diaphragmatic movement. 
level hardly moves more than half to one inch during quiet breathing. If we assume an " average level" half way between the expiratory and inspiratory levels, we can examine the relation of this " average level during quiet breathing" to the highest and lowest levels in maximum expiration and inspiration. As Hofbauer (1921) and Livingstone (1928) have shown, the level of the diaphragm shifts upwards when the position and the patient changes from sitting to lying. This alteration, which is caused by the pressure of the abdominal contents, was confirmed in all our subjects. When the subject was sitting, the " average level" was, as a rule, near the inspiratory limit and not farther from it than one quarter of the total range ; when he changed to the supine position the "average level" shifted upwards and remained in the upper half of the total range, very often not more than one quarter of the total range from the expiratory limit.

When abdominal pressure was applied in the sitting position, the "average level" moved upwards in most cases, but not higher than midway between the expiratory and inspiratory limits, as shown in Fig. 2. Thus in sitting position external pressure by a belt has a similar influence on the "average level" as the pressure of the abdominal contents when the subject is lying down.

Range of movement during quiet breathing.This was measured in three normal and four emphysematous subjects. No gross differences were found between the two groups. Fig. 3 shows the changes observed in a normal subject in the sitting position. It was found that costal pressure regularly increased the range between 50 per cent and 100 per cent. This increase occurred mainly in the central portions of the diaphragm. Abdominal pressure had the opposite effect: the diaphragm moved only over a range of a few millimetres, and in one case it did not move at all (an observation mentioned by Warner and Doidge, 1939). It was thought that moderate pressure, as opposed to the firm pressure used in our experiments, might have a different effect on the level and range of the diaphragm, but this was not the case. Either there was no change at all, or the change lay in the same direction as under firm pressure but was less pronounced.

Vital capacity.-This was recorded in nine normal subjects and five emphysematous patients of the severe type (see Table). Costal pressure always caused a pronounced decrease of the vital capacity, whereas the reduction by abdominal pressure was much less. In sixteen of the twentyseven experiments it was 6 per cent or less, and in all but one less than the reduction by costal pressure. This is remarkable, because the upwards shift of the diaphragm by the abdominal belt was very pronounced. The emphysematous patients reacted in the same way as the normal subjects.

TABLE

VITAL CAPACITY (IN C CM.) IN SITTING AND IN SUPINE POSITIONS, AND ITS PERCENTAGE DECREASE DURING COSTAL AND ABDOMINAL PRESSURE

\begin{tabular}{c|c|c|c||c|c|c}
\hline & \multicolumn{3}{|c||}{ Sitting position } & \multicolumn{3}{c}{ Supine position } \\
\cline { 2 - 5 } Name & $\begin{array}{l}\text { Without } \\
\text { external } \\
\text { pressure }\end{array}$ & $\begin{array}{c}\text { Percentage } \\
\text { decrease during } \\
\text { costal pressure }\end{array}$ & $\begin{array}{c}\text { Percentage } \\
\text { decrease during } \\
\text { abdominal pressure }\end{array}$ & $\begin{array}{l}\text { Without } \\
\text { external } \\
\text { pressure }\end{array}$ & $\begin{array}{c}\text { Percentage } \\
\text { decrease during } \\
\text { costal pressure }\end{array}$ & $\begin{array}{c}\text { Percentage } \\
\text { decrease during } \\
\text { abdominal pressure }\end{array}$ \\
\hline
\end{tabular}

\begin{tabular}{l|l|r|} 
Di. & 4,200 & 10 \\
Ke. & 4,590 & 13 \\
Mo. & 4,530 & 9 \\
Ju. & 4,370 & 18 \\
Co. & 3,580 & 14 \\
Fe. & 4,170 & 23 \\
Ho. & 5,320 & 8 \\
Wa. & 4,400 & 34 \\
Ha. & 3,370 & 11
\end{tabular}

Normal position

\begin{tabular}{|c|c|c|c|c|c|c|}
\hline \multirow[b]{2}{*}{$\begin{array}{l}\text { Sa. } \\
\text { St. } \\
\text { Mi. } \\
\text { Ro. } \\
\text { Ed. }\end{array}$} & \multirow[b]{2}{*}{$\begin{array}{l}2,450 \\
1,740 \\
2,270 \\
2,820 \\
1,740\end{array}$} & \multicolumn{3}{|c|}{ Emphysematous subjects } & \multirow[b]{2}{*}{$\begin{array}{r}29 \\
10 \\
26 \\
20 \\
9\end{array}$} & \multirow[b]{2}{*}{$\begin{array}{r}13 \\
21 \\
6 \\
+7\end{array}$} \\
\hline & & $\begin{array}{r}12 \\
13 \\
33 \\
20 \\
6\end{array}$ & $\begin{array}{r}16 \\
29 \\
29 \\
10 \\
1\end{array}$ & $\begin{array}{l}2,010 \\
1,690 \\
1,870 \\
2,820 \\
1,740\end{array}$ & & \\
\hline
\end{tabular}

\begin{tabular}{|c|c|c|c|}
\hline \multicolumn{4}{|c|}{ - } \\
\hline $\begin{array}{r}1 \\
8 \\
3 \\
4 \\
1 \\
14 \\
8 \\
11 \\
+1\end{array}$ & $\begin{array}{l}4,110 \\
4,260 \\
4,440 \\
4,360 \\
3,200 \\
4,060 \\
5,080 \\
4,160 \\
3,390\end{array}$ & $\begin{array}{l}16 \\
16 \\
18 \\
31 \\
24 \\
34 \\
20 \\
26 \\
10\end{array}$ & $\begin{array}{r}+2 \\
6 \\
5 \\
27 \\
6 \\
9 \\
5 \\
17 \\
2\end{array}$ \\
\hline \multicolumn{4}{|c|}{ physematous subjects } \\
\hline $\begin{array}{r}16 \\
2 \\
29 \\
10 \\
1\end{array}$ & $\begin{array}{l}2,010 \\
1,690 \\
1,870 \\
2,820 \\
1,740\end{array}$ & $\begin{array}{r}29 \\
10 \\
26 \\
20 \\
9\end{array}$ & $\begin{array}{r}21 \\
6 \\
+7\end{array}$ \\
\hline
\end{tabular}




\section{Discussion}

It seems surprising that the range of diaphragmatic movement can be widened beyond the limits reached by extreme voluntary effort. This holds good for both normal and emphysematous subjects, but in the latter the inspiratory limit cannot be extended under external pressure, probably because it is already abnormally low and has reached its extreme position. This observation may have diagnostic value.

The simultaneous observation of vital capacity and diaphragmatic action permits various conclusions :

1. When costal pressure limits inspiratory rib movement the diaphragm can be lowered more than before and its excursions become greater. Nevertheless the vital capacity is considerably reduced. This shows that the stronger diaphragmatic action compensates only partly for the limitation of rib movement.

2. When abdominal pressure forces the diaphragm upwards and reduces its excursions, the vital capacity decreases very little. This shows that some other factor must have compensated for the loss of diaphragmatic action. Increased rib movement is probably the factor, and evidence for this assumption will be presented elsewhere. It follows that loss of diaphragmatic function by external pressure can be compensated more easily by rib movement than loss of rib movement by diaphragmatic function.

3. In no case has costal or abdominal pressure increased the vital capacity. This is in accordance with the observations of Warner and Doidge (1939). Alexander and Kountz (1934) and Alexander (1936) describe an increase of the vital capacity that occurred after the patients had worn an abdominal belt for a long period. Apparently the measurements were taken without the belt pressure. I have reported (Herxheimer, 1946) a similar increase of the vital capacity after a costal belt had been worn for several days to several weeks. All the authors concerned report that most patients experienced relief under the treatment.

It is difficult to offer an explanation for the subjective improvement during compression, and also for the subsequent increase of the vital capacity. One may be tempted to assume that belt pressure causes certain parts of the lungs to be ventilated more than before. In many cases emphysema affects only some parts of the lungs, for instance the anterior margin. If the breathing movements, altered by belt pressure, ventilated other regions more an improvement of the gas exchange could be expected. If this were so it would be necessary to find the exact localization of the emphy= sematous changes in every case in order to devise rational treatment.

The increase of vital capacity which has been found after removal of the belt may be due to the additional respiratory training the compression bas produced. As has been shown, the costal belt moves the diaphragm to greater excursions; the abdominal belt, on the other hand, immobilizes the diaphragm to some extent and will encourage greater movements of the ribs. It is possible that the greater ranges of movement thus acquired are retained after removal of the pressure, and that they increase the vital capacity. I have been able to show a similar effect in four untrained normal subjects (Herxheimer, 1946), but not in four other normal persons especially well trained in respiratory exercises.

\section{SUMMARY}

1. The range of the diaphragmatic movements has been examined under costal- and abdominalbelt pressure in nine normal and in thirty-four emphysematous subjects.

2. Costal pressure enabled the normal but not the emphysematous subject to lower the diaphragm more on maximum inspiration.

3. Abdominal pressure enabled both groups to push the diaphragm higher up in maximum expiration; during quiet breathing it restricted the diaphragmatic movements to a minimum.

4. In no case did improvement of the vital capacity occur. Under costal pressure the vital capacity was always considerably reduced. Its reduction under abdominal pressure was much smaller, in the majority of experiments 6 per cent or less.

5. The application of these findings to the belt treatment of emphysema is discussed.

I am indebted to Dr. E. E. Pochin for valuable criticisms, and to Dr. Andrew Morland for a number of patients from his out-patients clinic.

\section{REFERENCES}

Alexander, H. L. (1936). Internat. Clin., 4, 211. Alexander, H. L., and Kountz, W. B. (1934). Amer. J. med. Sci., $187,687$.

Christie, R. V. (1933). J. clin. Invest., 12, 974.

Grossmann, M., and Herxheimer, H. (1948). Brit. J. Radiol. (In press.)

Herxheimer, H. (1946). Oral comm., Physiol. Soc.

Hofbauer, L. (1921). "Atmungspathologie and Therapie." Berlin and Vienna: Springer.

Livingstone, J. L. (1928). Lancet, 1, 754.

Warner, W. P., and Doidge, W. A. (1939). Trans. Amer. clin. climatol. Ass., 54, 52. 